Barclay AJG, Foster A, Sommer A. Vitamin A supplements and mortality related to measles: randomised clinical trial. B.117 1987;294:294-6.

6 W'hittle HC, Smith JS, Kogbe OI, Dossetor J, Duggan M. Severe ulcerative herpes of mouth and eve following measles. Trans $R$ Soc Trop Med Hyg 1979;73:66-9.

Aaby P, Bukh J, Hoff G, et al. High measles mortality in infancy related to intensity of exposure. F Pediatr 1986;109:40-4

8 Ellison JB. Intensive vitamin therapy in measles. BM7 1932;ii:708-11.

9 Hussey GD, Klein $M$. A randomized controlled trial of vitamin $A$ in children with severe measles. N Engl Med 1990;323:160-4

Markowitz LE Nzilambi N, Driskell WJ, et al. Vitamin A levels and mortality among hospitalized measles patients, Kinshasa, Zaire. F Trop Pediatr 1989;35:109-12.
11 Nutritional Blindness Prevention Project. Characterization of vitamin A deficiency and xerophthalmia and the design of an effective intervention program. Indonesia: Directorate of Nutrition, Ministry of Health, 1980.

12 Tielsch JM, Sommer A. The epidemiology of vitamin A deficiency and xerophthalmia. Annu Rev Nutr 1984;4:183-205.

3 Inua $M$, Duggan MB, West CE, et al. Post measles corneal ulceration in children in northern Nigeria: the role of vitamin A, malnutrition and measles. Ann Trop Paediatr 1983;3:181-91.

4 World Health Organisation/Unicef. Expanded programme on immunization: programme for the prevention of blindness nutrition. Joint $\mathrm{WHO} /$ Unicef statement: vitamin A for measles. World Health Organisation Weekly Epidemiological Record 1987;62:133-4.

\title{
HIV infection in women
}

\section{Needs early identification to limit complications}

This year's dedication of World AIDS Day to women infected with HIV is a time to remind ourselves that the reported number of such women in the United Kingdom now totals 1572 (Communicable Disease Surveillance Centre, September 1990), with the true number undoubtedly higher. Recent notifications indicate that women are contributing about one third of new cases in Scotland and one sixth in England, Wales, and Northern Ireland. The importance of the low but rising numbers of women infected by heterosexual contact is undetermined. ${ }^{12}$ It may be premature to suggest that these figures reflect a shift of HIV into the low risk heterosexual population, but they underline the point that HIV infection and AIDS are no longer a problem contained within defined (male) risk groups. Indeed, if the pattern of spread mirrors that seen in the Third World the marker of risk behaviour in women may be unprotected vaginal intercourse, hardly an uncommon event and of little use in defining risk groups.

Women aged 15-44, encompassing four fifths of HIV seropositive women, cross the medical threshold commonly. Their needs for family planning, antenatal care, and the gynaecological problems of menstruation, fertility, and the menopause will therefore require general practitioners, obstetricians, and gynaecologists to see more apparently healthy women infected with HIV in the future. Their detection by screening becomes ever more important, especially as evidence accumulates of the successful use of zidovudine to delay the onset of AIDS in infected patients. ${ }^{3}$ What are the particular problems of such women and what are the obstetric and gynaecological consequences of perhaps 10 years of infection?

Cervical abnormalities are common in women infected with HIV ${ }^{+6}$ but whether HIV is therefore a causal factor in the development of genital tract neoplasia has awaited investigation by controlled trials. Recent reports suggest that HIV infection confers added risk through immunocompromise (M L Muggiasca et al, 5th international conference on AIDS, Montreal, 1989) in a similar fashion to long term immunosuppressive treatment, ${ }^{7}$ but reports differ on the degree of immunosuppression required. The risk rises with clinical evidence of HIV disease and correlates with a falling CD4+ lymphocyte count (J R Smith et al, S H Vermund et al, A Schafer et al, N J Tarricone et al, 6th international conference on AIDS, San Francisco, 1990). Until we know at what level of immunosuppression complications arise there is a need for regular cervical screening in women infected with HIV.

Data on infections of the lower genital tract are difficult to find, and the concept that recurrent genital infection is a marker of high risk behaviour and an indication for HIV testing has not been as well appreciated in gynaecology as it has in genitourinary clinics. ${ }^{8}$ The association of genital ulcerative disease and HIV infection observed in Africa has been seen in the West; even after controlling for high risk behaviour ulceration seems to be more common among women infected with HIV ( $\mathrm{K}$ Chirgwin et al, 5th international conference on ÄDS, Montreal, 1989). A five year retrospective review of infected women has shown a high rate of previous sexually transmitted disease and a new infection rate of $23 \%$, with genital herpes becoming progressively more common as the CD4+ lymphocyte count falls (J Anderson et $a l$, 6th international conference on AIDS, San Francisco, 1990). With the spectre of tuberculosis and HIV infection appearing in the Third World, ${ }^{9}$ gynaecologists can now expect to see cases of pelvic tuberculosis, a rare condition in the United Kingdom. There is no information about the implications for the other more common causes of chronic pelvic inflammatory disease and little information on HIV infection and ovarian malignancy (A Schafer and W Friedmann, 4th international conference on AIDS, Stockholm, 1988) or the common presenting gynaecological symptoms of menorrhagia, dysmenorrhoea, and dyspareunia.

At present the management of pregnancy in women infected with HIV differs little from that in uninfected women. Perinatal transmission of HIV occurs in $15-33 \%$ of pregnancies, so the criteria for termination are certainly met. ${ }^{10}$ Some doctors will find it strange, therefore, that infection with HIV seems to take second place to socioeconomic considerations in determining termination requests, with little difference in the request rate between women who are and are not infected in high risk groups (M Barbacci et al, 5th international conference on AIDS, Montreal, 1989). ${ }^{112}$ Infected women who elect to continue a pregnancy can be told that there is no evidence that babies born in the West are at increased risk of prematurity or growth retardation. ${ }^{13}$ The question of whether pregnancy accelerates the course of HIV infection is unanswered, with conflicting findings from France and the United States (J F Delfraisey et al, 5th international conference on AIDS, Montreal, 1989; A Berebbi et al, K Bledsoe et al, 6th international conference on AIDS, San Francisco, 1990). Consequently, there is no consensus on how and when those wishing to conceive should be advised. Appreciable numbers of women seek pregnancy knowing that they are positive for antibodies to HIV and will fail to use effective contraception despite counselling $(\mathrm{M} \mathrm{H}$ Kaplan et al, 5th international conference on AIDS, Montreal, 1989). Are gynaecologists prepared to support such women who are determined to proceed with a pregnancy and, more controversially, help those who request infertility advice? The question of pregnancy in the uninfected spouse of a man infected with HIV has not been addressed.

We have progressed from the negative attitudes towards HIV infection and AIDS seen five years ago. A recent commentary lamented the self fulfilling nihilism that labels 
patients infected with HIV as lost causes and advocated the consideration of antiviral treatment in asymptomatic individuals and prophylaxis against AIDS related infections. ${ }^{1+}$ Such policies require early identification of HIV infection, and obstetricians and gynaecologists must take note that their contact with women infected with HIV will increase.

STEPHEN NORMAN Research Assistant in Gynaecology JOHN STUDD

King's College Hospital Consultant Gynaecologist

London SE5 9RS

MARGARET JOHNSON Consultant in HIV/AIDS

Department of Thoracic Medicine,

Royal Free Hospital,

London NW3 2QQ

1 Skegg DCG. Heterosexually acquired HIV infection. BMJ 1989;298:401-2.
Public Health Laboratory Service Working Group. Prevalence of HIV antibods in high and low risk groups in England. B.117 1989:298:422-3.

3 Volberding PA, Lagakas SW. Koch MA, et al. Zidovudine in asymptomatic human immunodeficiency virus infection. A controlled trial in persons with fewer than $500 \mathrm{CD} 4$ positive cells per cubic millimeter N Englf uld 1990:322:941-9.

4 Bradbeer C. Is infection with HIV a risk factor for cervical intraepithelial neoplasia? Lancet 1987;ii: $1277-8$.

Spurett B, Shellev-Jones D, Stewart G. Cervical dysplasia and HIV infection. Lancet 1988;1:237-8.

6 Byrne M, Taylor-Robinson D, Harris JRW. Cervical dysplasia and HIV infection. Lanct $1988 ; \mathrm{i}: 239$.

Alloub MI, Barr BBB, McLaren KM, Smith IW', Bunny MH, Smart GE. Human papillomavirus and cervical intraepithelial neoplasia in women with renal allografts. B.117 1989;298:153-5.

8 Anonymous. HIV infection in patients attending clinics for sexually transmitted diseases in England and $\mathrm{W}$ ales. Collaborative study by consultants in genitourinary medicine and the Public Health Laboratory Service. BMF 1989;298:415-8.

9 Harries AD. Tuberculosis and human immunodeficiency virus infection in developing countries. Lancet 1990;335:387-9.

10 Webster A, Johnson M. Human immunodeficiency virus infection. In: Studd J, ed. Progress in obstetrics and gynaecology. Vol 8. London: Churchill Livingstone, 1990:175-90.

11 Selwyn PA, Carter RJ, Schoenbaum EE, Robertson VJ, Klein RS, Rogers MF. Knowledge of HIV antibody status and decisions to continue or terminate pregnancy among intravenous drug abusers. FAMA 1989:261:3567-71.

12 Johnston FD, Brettle RP, MacCullum LR, Mok J, Peutherer JF, Burns S. Women's knowledge of their HIV antibody state: its effect on their decision whether to continue the pregnancy. BMF 1990; 300:23-4

13 John FD, MacCullum L, Brettle M, Inglis JM, Peutherer JF. Does infection with HIV affect the outcome of pregnancy? BMF 1988;296:467.

14 Squire SB, Johnson MA. Early diagnosis of HIV infection. Br f Hosp Med 1990;44:9.

\section{Menière's disease}

\section{Medical treatment should help $80 \%$ of those affected}

Menière's disease is a syndrome of hearing impairment, tinnitus, and episodic vertigo. Its association with dilatation of the membranous labyrinth was first recognised by Hallpike and Cairns in 1938.' This expansion of the endolymphatic compartment, referred to as endolymphatic hydrops, is usually unilateral, although some people estimate that bilateral hydrops occurs in $20-50 \%$ of cases, ${ }^{2-5}$ depending in part on the criteria used to accept lesions in the other ear. ${ }^{6}$

Endolymphatic hydrops encompasses more than Menière's disease. It may be asymptomatic; it may affect only the cochlea-impairing hearing; it may be confined to the vestibular labyrinth; and it is sometimes secondary to injuries or diseases of the otic capsule. To the otologist Menière's disease is endolymphatic hydrops that is idiopathic and symptomatic. ${ }^{78}$ The diagnosis is usually inferred from the history, and it is supported by the audiometric finding of a fluctuating low tone sensorineural hearing impairment. Although not essential to establish a diagnosis, the hydrops may be confirmed by electrocochleography, which shows typical abnormalities attributed to mechanical distortion of the basilar membrane. ${ }^{9}$

Unfortunately, few patients are identified with this degree of rigour before they are offered medical treatment. The disorder is overdiagnosed by doctors who apply lax criteria to many patients who have vertigo and tinnitus because of other reasons. By the time patients are referred for otological scrutiny they have invariably been treated. This poses an inescapable epidemiological difficulty. The patients whose untreated disease could be studied are not available to the otologists with the facilities to apply sufficiently rigid criteria for accurate diagnosis, so too little is known about the uncontaminated natural history. The added problems inherent in analysing the response to treatment of any chronic disorder with a benign course given to spontaneous unpredictable remissions, especially when those responses are mainly subjective, explain why no medical treatment has lent itself to the rigours of a fully satisfactory clinical trial.

Medical treatment should be considered for all patients initially, and four fifths of patients should become sufficiently free from attacks of vertigo to escape surgery. The options available exploit different ideas about the cause of the underlying disorder. The advocacy of low salt diets, combined with chlorothiazide diuretics (and potassium replacement), is based on an electrolyte derangement theory of hydropic aetiology; and, anecdotally, this treatment does seem to help. A conventional first line of medical treatment is a vasodilator, usually betahistine $8-16 \mathrm{mg}$ three times a day. This is based on the theory that ischaemia of the stria vascularis, a site of production of endolymph in the cochlea, is the first link in another chain of cause. Vasodilator drugs, reputed to increase cochlear blood flow, ${ }^{10}$ are therefore prescribed to break it. Patients with peptic ulceration, who should not take betahistine, may be given nicotinic acid in a dose sufficient to cause blushing (usually about $100 \mathrm{mg}$ four times a day). If after about a month there is no respite in the frequency or severity of vertigo a diet with as low a salt content as possible may be advised, combined with chlorothiazide and potassium replacement given daily, or every other day. Treatment with betahistine may be continued, or, better, it can be stopped while the electrolyte controlling regimen is assessed on its own, to be reintroduced if control is not satisfactory.

Vestibular sedatives, such as prochlorperazine and cinnarizine are useful remedies for the symptoms. They may be taken regularly by mouth (prochlorperazine $10 \mathrm{mg}$ three times a day, or cinnarizine $15 \mathrm{mg}$ three times a day) during periods when attacks are frequent to lessen their severity. They may also be used for short periods between trials of vasodilators and electrolyte modification. Theoretically the antihistaminic action of cinnarizine should reduce the efficacy of betahistine, but in fact the combination does not cause problems. During acute attacks, when patients may be unable to take drugs by mouth because of nausea and vomiting, vestibular sedatives may be given by injection or as suppositories.

Operative measures are considered when two or three different regimens of medical treatment tried for a few months have failed to control the vertigo. No more than a fifth of patients are likely to need surgery. Efforts to standardise the reporting of results emerged from the American Academy of Ophthalmology and Otolaryngology in 1972, ${ }^{11}$ modified in 